\title{
Análise de tradução automática português-Libras no contexto do edital do Enem 2018
}

\author{
Priscila R. F. Bedana ${ }^{1}$, Fernando A. Freitas ${ }^{1,2}$, Sarajane M. Peres $^{2}$, Felipe V. Barbosa ${ }^{2}$ \\ ${ }^{1}$ Instituto Federal de São Paulo (IFSP - Campus Campinas) \\ Rodovia Dom Pedro I, Km 143,6 - B. Amarais - 13.069-9010 - Campinas - SP - Brasil \\ ${ }^{2}$ Programa de Pós-graduação em Sistemas de Informação - Universidade de São Paulo \\ Rua Arlindo Béttio, 1000, Ermelino Matarazzo - 03.828-000 - São Paulo - SP \\ ${ }^{3}$ Departamento de Linguística - Universidade de São Paulo \\ Av. Prof. Luciano Gualberto, 403 - 05.508-010 - São Paulo - SP \\ priscilafbedana@hotmail.com, fernando.freitas@ifsp.edu.br, \\ \{sarajane, felipebarbosa\}@usp.br
}

\begin{abstract}
In this paper, automatic Portuguese-Libras translations are analyzed in the educational context of deaf people. The speeches in Libras, obtained in the translation functions, are uttered by an avatar. The communication promoted by the avatars is contrasted with translations offered by human interpreters and analyzed in relation to the use of Signed Portuguese and fingerspelling, and to the contextualization and correctness of the information being transmitted. The analysis revealed that the translation technology available for such communication modality still does not present maturity for using in critical contexts in which mistranslations can lead to losses for users, as it is the case in the official guidelines referring to the Brazilian National High School Examination.
\end{abstract}

Resumo. Neste artigo, traduções português-Libras são analisadas no contexto educacional da pessoa surda. Os discursos em Libras obtidos na tradução automática são apresentados via avatares. A comunicação promovida pelos avatares é contrastada com traduções oferecidas por intérpretes humanos, e analisada em relação ao uso de datilologia e português sinalizado, e à contextualização e corretude da informação transmitida. A análise revelou que a tecnologia de tradução disponível para tal modalidade de comunicação não possui maturidade para uso em contextos críticos nos quais um equívoco de tradução possa levar a perdas para usuários, como é o caso nas orientações oficiais referentes ao Exame Nacional do Ensino Médio.

\section{Introdução}

A Língua Brasileira de Sinais (Libras), língua de comunicação e expressão da comunidade surda no Brasil, foi reconhecida pela Lei $n^{0} 10.436$ de 2002 [Brasil 2002], e regulamentada pelo decreto $\mathrm{n}^{0} 5.626$ de 2005 [Brasil 2005]. Em 2015, foi criada a Lei $\mathrm{n}^{\mathrm{o}}$ 13.146 [Brasil 2015], dentre outras funções, para assegurar acessibilidade nos espaços de informação e comunicação do país. Tais espaços incluem o meio digital, exigindo a implementação de acessibilidade em websites de órgãos do governo e de empresas. $\mathrm{O}$ atendimento ao surdo passa a ser prioritário e acessível, seja em espaço físico ou em meio 
digital, gerando a demanda pela presença um intérprete que deve ser habilitado para a execução da tradução e interpretação entre a Libras e a língua portuguesa.

A presença desse profissional em todos os espaços públicos ainda não é plenamente viável dos pontos de vista financeiro e de recursos humanos. Por um lado, a demanda pelo serviço não apresenta recorrência que justifique a disponibilização de intérpretes em tempo integral. Por outro lado, a aquisição da Libras como segunda língua não é trivial, o que dificulta a contratação de pessoas com conhecimentos em Libras para preencher as posições que atuam no atendimento ao público.

Um exemplo positivo da acessibilidade para surdo é o contexto do Enem - Exame Nacional do Ensino Médio. Desde 2015, o instituto responsável pelo exame, o Inep, tem dado atenção à questão da acessibilidade na educação para surdos. Gradativamente, recursos como editais em Libras e videoprovas estão contribuindo para a equidade entre candidatos surdos e ouvintes, sob a chancela do selo Enem em Libras ${ }^{1}$. Entretanto, ainda que de alto valor agregado, a produção $a d$ hoc de conteúdo em Libras não alcança a escala necessária para promover acessibilidade e a inclusão plena dos surdos, o que faz perdurar a diferença nas condições de acesso ao conhecimento entre uma pessoa ouvinte e uma pessoa surda, colocando o surdo em desvantagem na busca por oportunidades.

O avanço em processamento de língua natural, reconhecimento de padrões e processamento gráfico tem permitido a criação de softwares que promovem acessibilidade. Dentre eles estão aqueles que realizam tradução e usam avatares ${ }^{2}$ para comunicar o discurso em língua de sinais. Tais softwares versionam línguas e são uma alternativa para promover a acessibilidade, inclusão e interação social [Machado et al. 2016]. Com o surgimento desses softwares, assoma a preocupação com a qualidade das suas traduções. Os questionamentos sobre a coerência e confiabilidade das traduções emergem entre especialistas e usuários, e as discussões se voltam para os impactos da qualidade do serviço de tradução e que consequências são geradas na disseminação de informação equivocada.

Neste artigo, são apresentados os resultados de uma análise comparativa da qualidade de tradução automática português-Libras oferecida por dois softwares e por um intérprete humano, no contexto do Edital do Enem 2018. Este artigo segue organizado em cinco seções: um breve referencial teórico para dar suporte ao entendimento da análise realizada; trabalhos correlatos para posicionamento desta iniciativa diante de outras similares; descrição do método e motivação para decisões tomadas durante a elaboração da análise; os principais resultados e discussões; as considerações finais.

\section{A estrutura da Libras}

A Libras é uma língua de modalidade visual-motora com gramática própria [de Quadros and Schmiedt 2006] reconhecida como meio legal de comunicação no Brasil. Ela não é uma adaptação do português. Suas características e estrutura surgiram naturalmente das interações entre os seus usuários (pessoas surdas), assim como ocorreu com outras línguas de sinais. Nas línguas de sinais faz-se uso da articulação de sinais formados pela combinação de cinco parâmetros [Stokoe 1980, Battison 1974]: formato que as mãos assumem durante a execução do sinal (configuração de mãos); local onde o

\footnotetext{
${ }^{1}$ http://portal.inep.gov.br/educacao-basica/enem/enem-em-libras

${ }^{2}$ Avatar é uma representação corporal de alguém no meio digital. Neste artigo, um intérprete virtual.
} 
VIII Congresso Brasileiro de Informática na Educação (CBIE 2019)

Anais do XXX Simpósio Brasileiro de Informática na Educação (SBIE 2019)

sinal é realizado no espaço tridimensional (ponto de articulação); movimento realizado pelas mãos, no espaço tridimensional, durante a sinalização (movimento); direção assumida pela palma da mão na execução de um sinal e a direção na que esse sinal é executado (orientação); e posição e movimentos da cabeça, posição e movimentos do corpo, olhar e expressões faciais (expressões não manuais).

Para que um discurso em língua de sinais passe a mensagem correta, o conjunto completo dos parâmetros formadores de um sinal e da sintaxe da língua devem ser observados. Combinações erradas ou a ausência de um parâmetro podem mudar a coerência do discurso ou mesmo o seu sentido. Expressões faciais, por exemplo, assumem o papel de representar elementos morfológicos e sintáticos em uma sentença [de Almeida Freitas et al. 2017]. Ignorar um parâmetro como esse pode levar à execução de uma sentença agramatical, eventualmente tornando-a ininteligível [de Quadros and Karnopp 2009, Arroteia 2005].

No contexto histórico da Educação de Surdos, o português sinalizado foi utilizado como uma ferramenta de comunicação que usava o português e sinais da língua de sinais de forma concomitante, na tentativa de representar as estruturas do português em língua de sinais [de Lacerda 1998]. No português sinalizado, para cada palavra usada no discurso em português, executa-se um sinal em Libras, levando à criação de uma cópia da língua oral predominante. Do ponto de vista linguístico, o uso do português sinalizado em substituição aos recursos próprios da língua de sinais produz um sistema de comunicação artificial que não contempla as línguas envolvidas e pode indicar falta de domínio da língua de sinais. A diferença estrutural entre a Libras e o português sinalizado pode ser observada na Figura 1. Nesta figura, as sentenças são transcritas em glosas ${ }^{3}$.

\begin{tabular}{l|c}
\hline Português & A menina foi muito ousada, ela persistiu até vencer o campeonato. \\
\hline Português sinalizado & MULHER + PEQUENA + MUITO + CORAJOSA + LUTAR + ATÉ + VENCER + CAMPEONATO \\
\hline Libras & MULHER + PEQUENA + CORAJOSA + MUITO + LUTAR + CAMPEONATO + VENCER + CONSEGUIR \\
\hline
\end{tabular}

Figura 1. Apresentação de sentenças proferidas usando português sinalizado e Libras, com transcrições representadas em glosas

\section{Trabalhos correlatos}

Como na análise descrita neste artigo, as discussões apresentadas em [Vieira et al. 2014] e [Santos 2017] versam sobre a qualidade de softwares de tradução português-Libras. No primeiro caso, os softwares ProDeaf e Hand Talk são analisados em termos da aceitabilidade por parte de usuários surdos e ouvintes e da qualidade da funcionalidade que sintetiza expressões não manuais. Os resultados foram positivos para a aceitabilidade, porém levantaram limitações em relação à qualidade da síntese e aplicação do parâmetro referente às expressões faciais. O segundo caso acrescenta o aplicativo Rybená no rol de softwares analisados e segue uma abordagem mais próxima à apresentada no presente artigo, porém realiza avaliações simplificadas sobre três pequenas sentenças extraídas do Exame Nacional do Prolibras de 2012. Ainda que diante de uma amostra reduzida, os destaques dos autores foram para o uso do português sinalizado, tradução incompleta e carência de exploração do parâmetro de expressões não manuais. Estudos recentes sobre

\footnotetext{
${ }^{3}$ Glosa é um recurso usado para representar a transcrição de uma sentença [Mccleary et al. 2010].
} 
VIII Congresso Brasileiro de Informática na Educação (CBIE 2019)

Anais do XXX Simpósio Brasileiro de Informática na Educação (SBIE 2019)

softwares tradutores da língua oral para língua de sinais, com uso de avatares, também é explorado no contexto internacional. Traduções da língua oral para língua de sinais árabe, indiana e turca são apresentadas em [El-Gayyar et al. 2016], [Nair et al. 2016] e [Eryiğit et al. 2016], respectivamente. Característica comum a todos esses trabalhos é a constatação de que esses softwares ainda estão em seus estágios iniciais e que testes envolvendo usuários da comunidade surda são essenciais e precisam ser mais bem explorados.

\section{Método}

Este estudo segue preceitos da pesquisa qualitativa, com foco em avaliar o nível de compreensão de discursos proferido em língua de sinais. A análise utilizou a comparação de duas fontes automatizadas de produção do discurso e uma fonte não automatizada. Seguindo o exposto em [Bryman 2012], este estudo é caracterizado como a aplicação de uma abordagem de análise do discurso, ou seja o discurso em si é o foco de investigação. $O$ método de pesquisa está instanciado na Figura 2. O contexto das traduções é um conjunto de sentenças extraídas do edital oficial do Exame Nacional do Ensino Médio (Enem) de 2018. O conteúdo deste edital está disponível também em Libras, a partir da tradução realizada por intérpretes do Núcleo de Educação Online do Instituto Nacional de Educação de Surdos (NEO/INES) humano ${ }^{4}$. Essa tradução é usada neste estudo como referência, i.e., é assumida como uma tradução de alta compreensibilidade. As traduções automáticas são fornecidas por softwares tradutores "português-Libras", identificados como Avatar 1 e Avatar 2 e registrados de forma escrita por meio de glosas. As sentenças proferidas em Libras por intérpretes humanos são também transformadas em glosas. Dois autores deste artigo, fluentes em Libras e certificados pelo MEC por meio do Exame Prolibras [de Quadros et al. 2009], foram responsáveis pelas construção das glosas.

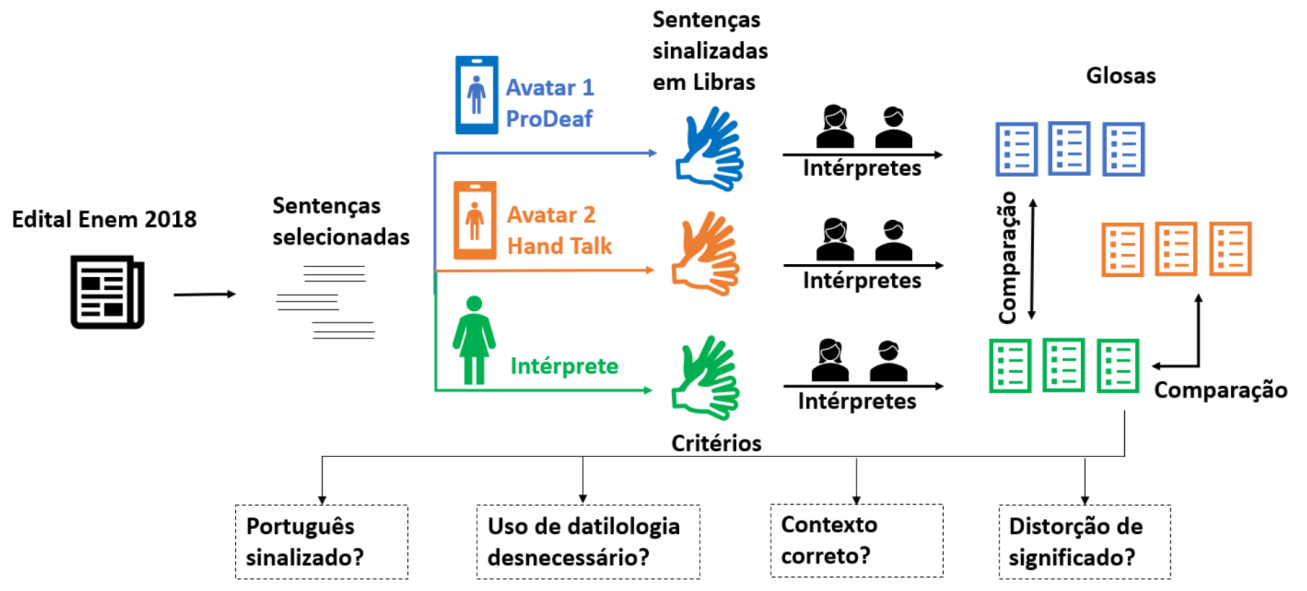

Figura 2. Passos seguidos nas análises das traduções automáticas

A tecnologia de tradutores automáticos para a LIBRAS é recente e existem poucos softwares disponíveis. Dentre os softwares existentes na época de realização deste estudo (ano 2018), destacavam-se o ProDeaf e o Hand Talk (descritos na Figura 3) - soluções nacionais gratuitas, disponibilizadas na forma de aplicativo móvel e para uso na web. Em 2018, essas soluções estavam em primeiro e segundo lugar em número de downloads, dentro de sua categoria, nos dois principais serviços de distribuição de soluções digitais para dispositivos móveis, por este motivo, foram selecionadas para compor este estudo.

\footnotetext{
${ }^{4}$ Os vídeos podem ser encontrados em https: / / www youtube. $\mathrm{com} /$ watch? $\mathrm{v}=$ __pk8BrTpmE
} 

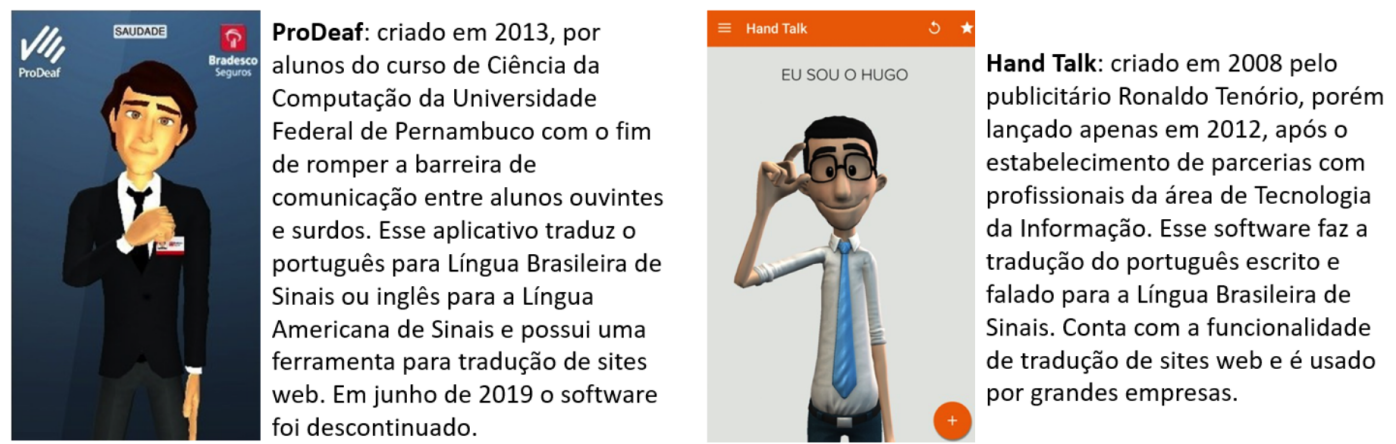

Figura 3. Descrição dos softwares que proveram as traduções automáticas

Na literatura sobre Libras, não existe um método ou conjunto de critérios para análise de qualidade de tradução de português para Libras. Desta forma, uma análise qualitativa do discurso foi realizada para avaliar a aderência da tradução ao uso da Libras ou ao uso do português sinalizado, o uso da datilologia, a contextualização adequada e a ocorrência de distorção do significado. Sentenças com informação crítica para o contexto de realização do Enem foram escolhidas para análise. Nessas sentenças a precisão da tradução é essencial, já que a interpretação equivocada do discurso nelas contido poderia gerar consequências negativas para um aluno que pretendia realizar a prova.

\section{Resultados e discussões}

Na comparação das traduções automáticas com a tradução feita pelos intérpretes, diversas passagens do Edital do Enem 2018 foram analisadas. Esta seção destaca algumas delas para ilustrar a complexidade envolvida no trabalho de tradução para uma língua de sinais. Por simplicidade: os softwares ProDeaf e Hand Talk são referenciados como Avatar 1 e Avatar 2, respectivamente; em comentários referentes aos dois softwares, o termo "avatares" é usado; os intérpretes são generalizados e referenciados como "intérprete".

Na Figura 4, diz respeito sobre ações necessárias para inscrição no exame, acompanhadas dos prazos nos quais elas devem ser realizadas. O foco desta análise está na forma como os tradutores lidam com números. Claramente, o Avatar 1 não foi capaz de interpretá-los, uma vez que a maioria deles diz respeito a datas e a tradução correspondeu exatamente à transcrição dos números. Esse procedimento torna a interpretação do conteúdo cansativa e confusa. O Avatar 2 criou uma tradução mais adequada, sendo capaz de reconhecer que o enunciado se refere a datas e traduzindo os números referentes a meses. No entanto, com exceção do mês "abril", todos os demais foram traduzidos usando datilologia ao invés de usar o sinal apropriado em Libras. A tradução feita pelo intérprete faz uso do contexto e solicita que o surdo analise a tabela, o que facilita a transmissão do conteúdo. A comparação das traduções deixa claro que a interação da informação e seu contexto representa um desafio para a automação. O conhecimento e experiência do intérprete foi crucial para prover uma boa tradução.

A sentença na Figura 5 informa os horários críticos do exame. É uma informação cuja interpretação gera consequências importantes para os candidatos. Nesse caso, novamente, a tradução do intérprete faz uso do contexto e solicita que o surdo acompanhe o cronograma em uma tabela. Então, a análise se resume a comparar o desempenho dos dois avatares. As traduções foram similares, porém, o Avatar 1 não reconheceu o conceito 
VIII Congresso Brasileiro de Informática na Educação (CBIE 2019)

Anais do XXX Simpósio Brasileiro de Informática na Educação (SBIE 2019)

\begin{tabular}{|c|c|}
\hline $\begin{array}{l}\text { Sentença } \\
\text { em análise }\end{array}$ & $\begin{array}{c}\text { 1.2 O Enem } 2018 \text { seguirá o cronograma abaixo: Solicitação de isenção da taxa de inscrição } 2 \text { a } \\
\text { 11/04/2018. Justificativa de ausência no Enem } 20172 \text { a 11/04/2018. Inscrições } 7 \text { a 18/05/2018. } \\
\text { Pagamento da taxa de inscrição } 7 \text { a 23/05/2018. Solicitação de Atendimento pelo Nome Social 28/05 a } \\
\text { 3/06/2018. Aplicação 4/11/2018 e 11/11/2018. }\end{array}$ \\
\hline $\begin{array}{l}\text { Glosa para } \\
\text { avatar } 1\end{array}$ & 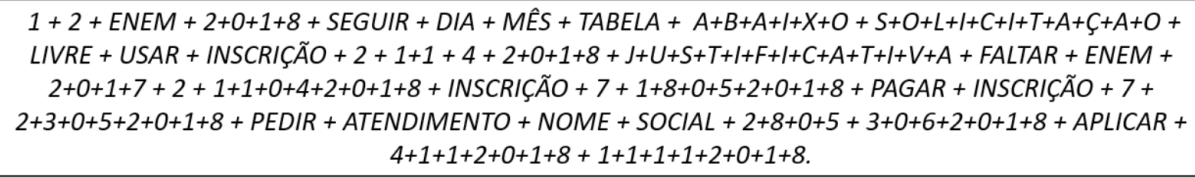 \\
\hline $\begin{array}{l}\text { Glosa para } \\
\text { avatar } 2\end{array}$ & 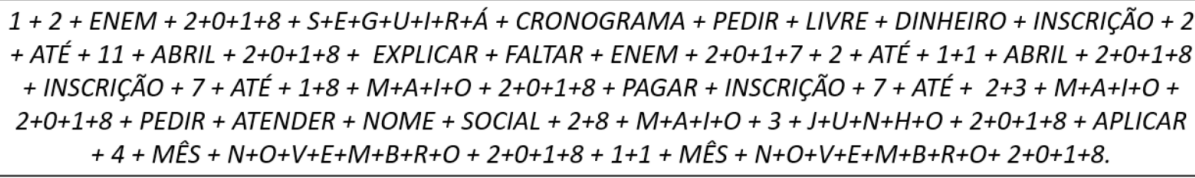 \\
\hline $\begin{array}{l}\text { Glosa para o } \\
\text { intérprete }\end{array}$ & ENEM + ACOMPANHARÁ + CRONOGRAMA + VER (TABELA DE VISUALIZAÇÃO NO VÍDEO) \\
\hline
\end{tabular}

Figura 4. Sentença referente a procedimentos de inscrição no exame e respectivas traduções. Foco para a tradução na presença de números e datas

de horário, visto que inseriu a letra " $H$ " usando datilologia, o que não seria o esperado. Em Libras, o conceito de horário é passado usando os números referentes à hora e o sinal de "horas no relógio" realizado no braço e, quando se trata de duração, usando face do sujeito que profere o discurso. Além disso, em ambas traduções, foi observada a inserção de um sinal para representar o conceito "ABAIXO". Porém, este é um conceito que não existe de forma isolada na Libras, necessitando sempre de um referencial, por exemplo, "MESA + ABAIXO" significando "objeto abaixo da mesa". Quaisquer referenciais usados pelos avatares teriam sido arbitrários representando um problema de contextualização da informação, visto que o objeto de referência não existe na sentença em análise.

\begin{tabular}{|c|c|}
\hline $\begin{array}{l}\text { Sentença } \\
\text { em análise }\end{array}$ & $\begin{array}{l}1.7 \text { A aplicação do Enem } 2018 \text { seguirá os horários abaixo: Abertura dos portões } 12 \mathrm{~h} \text {. Fechamento dos } \\
\text { portões } 13 \mathrm{~h} \text {. Início das provas } 13 \mathrm{~h} 30 \text {. Término das provas } 1 \text { - dia } 19 \mathrm{~h} \text {. Término das provas } 20 \text { dia } 18 \mathrm{~h} 30\end{array}$ \\
\hline $\begin{array}{l}\text { Glosa para } \\
\text { avatar } 1\end{array}$ & 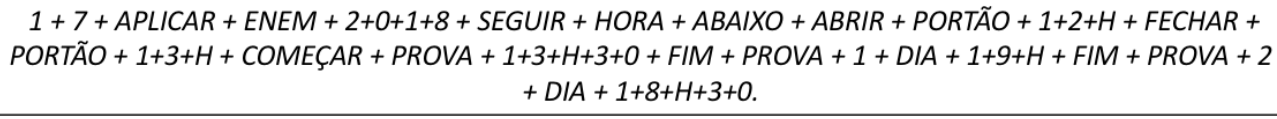 \\
\hline $\begin{array}{l}\text { Glosa para } \\
\text { avatar } 2\end{array}$ & 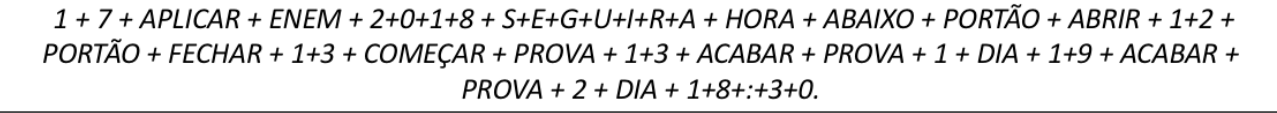 \\
\hline $\begin{array}{l}\text { Glosa para o } \\
\text { intérprete }\end{array}$ & RAMA + VER (TABELA). \\
\hline
\end{tabular}

Figura 5. Sentença indicando horários sobre a realização do exame. Foco na tradução na presença de horaŕios e na contextualização da informação

Na Figura 6, a sentença informa sobre obrigatoriedades de documentação. Nesta análise, observa-se um erro de tradução da palavra "VIA" cometido pelos avatares. Ambos não foram capazes de interpretar o significado da palavra no contexto da sentença e a traduziram como "RUA" e "AVENIDA". A palavra "DOCUMENTO" foi equivocadamente traduzida como "CARTÃO". O final da sentença é traduzido de maneira mais adequada pelo Avatar 2. Embora a tradução dos avatares tenham apresentado problemas por ter um caráter de tradução literal, ao menos a tradução do Avatar 2 pode ser considerada suficiente. A tradução do intérprete incorpora a habilidade de interpretação do contexto que lhe permite executar uma simplificação do conteúdo.

A sentença da Figura 7 diz respeito a uma regra sobre a relação entre a realização 
VIII Congresso Brasileiro de Informática na Educação (CBIE 2019)

Anais do XXX Simpósio Brasileiro de Informática na Educação (SBIE 2019)

\begin{tabular}{|c|c|}
\hline $\begin{array}{l}\text { Sentença } \\
\text { em análise }\end{array}$ & 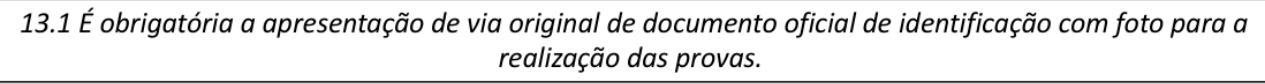 \\
\hline $\begin{array}{l}\text { Glosa para } \\
\text { avatar } 1\end{array}$ & $\begin{array}{c}1+3+1+\text { DEVER + APRESENTAR + RUA + OFICIAL + CARTÃO + OFICIAL + NOME + DAR + FOTO + MAIS + } \\
\text { FAZER + PROVA. }\end{array}$ \\
\hline $\begin{array}{l}\text { Glosa para } \\
\text { avatar } 2\end{array}$ & $\begin{array}{c}1+3+1+\text { DEVER + APRESENTAR + AVENIDA + OFICIAL + DOCUMENTO + OFICIAL + IDENTIFICAR + COM + } \\
\text { FOTO + FAZER + PROVA. }\end{array}$ \\
\hline $\begin{array}{l}\text { Glosa para o } \\
\text { intérprete }\end{array}$ & OBRIGATÓRIO + DOCUMENTO + FOTO + PRÓPRIO + ORIGINAL + MOSTRAR + PROVA. \\
\hline
\end{tabular}

Figura 6. Sentença referente à regra sobre obrigatoriedade de portar documentação adequada. Foco na simplificação (apropriada) da tradução

de inscrição e os candidatos que receberam isenção de taxa. Compreender essa regra é fundamental, já que a isenção de taxa pode induzir o candidato a achar que a inscrição não é necessária. Em termos sintáticos, os avatares fizeram um uso coerente dos sinais da Libras, com pouco uso de português sinalizado. O avatar 2 gerou um problema na tradução da passagem "será anterior". Ao usar os dois sinais "AVANÇAR/AVANTE" e "ANTES" em sequência, ele gera uma distorção da informação e induz à compreensão da sentença da seguinte forma: depois e antes, o participante poderá solicitar a isenção da taxa de inscrição. Contudo, apenas o intérprete fez a tradução correta da informação crítica da sentença. A tradução do intérprete estrutura a temporalidade usada no discurso explicitamente ordenando as ações com uso do sinal "depois", e reforça a necessidade da realização das ações com o sinal "precisar". Nesse caso, a tradução do intérprete incorpora uma explicação referente à regra presente no enunciado. Os avatares ainda não implementam esse tipo de recurso avançado de tradução.

\begin{tabular}{|c|c|}
\hline $\begin{array}{l}\text { Sentença } \\
\text { em análise }\end{array}$ & $\begin{array}{l}1.3 \text { No Enem 2018, a solicitação de isenção da taxa de inscrição será anterior à inscrição. Todos os } \\
\text { interessados em fazer o Enem 2018, isentos ou não, deverão fazer a inscrição. }\end{array}$ \\
\hline $\begin{array}{l}\text { Glosa para } \\
\text { avatar } 1\end{array}$ & $\begin{array}{c}1+3+E N E M+2+0+1+8+P E D I R+L I V R E+T A X A+U S A R+I N S C R I C ̧ \tilde{A} O+S+E+R+A+A N T E S+I N S C R I C ̧ A ̃ O+ \\
\text { TODOS + CERTO + FAZER + ENEM + 2+O+1+8+ LIVRE + TAXA + USAR + OU + PAGAR + NÃO + FAZER + } \\
\text { INSCRIÇÃO. }\end{array}$ \\
\hline $\begin{array}{l}\text { Glosa para } \\
\text { avatar } 2\end{array}$ & $\begin{array}{l}1+3+E N E M+2+O+1+8+P E D I R+D I N H E I R O+I N S C R I C C A ̃ O+A V A N C C A R+A N T E S+I N S C R I C C A ̃ O+T O D O S+ \\
\text { INTERESSE + FAZER + ENEM + 2+O+1+8+ I+S+E+N+T+O+S+O+U + NÃO + PRECISAR + FAZER + INSCRIÇÃO. }\end{array}$ \\
\hline $\begin{array}{l}\text { Glosa para o } \\
\text { intérprete }\end{array}$ & $\begin{array}{l}\text { ENEM + 2+0+1+8 + PEDIR INSCRIÇÃO + GRATUITA + DEPOIS + PRECISAR + INSCRIÇÃO + OFICIAL + TODOS + } \\
\text { ENEM + 2+0+1+8 + PAGAR + O+U + INSCRIÇÃO + ISENTA + PRECISAR + DEPOIS + INSCRIÇÃO + OFICIAL. }\end{array}$ \\
\hline
\end{tabular}

Figura 7. Sentença referente à regra que relaciona isenção de taxa e obrigatoriedade de inscrição no exame. Foco na precisão da informação transmitida

A última sentença diz respeito a regras de como proceder durante a realização da prova (Figura 8). Nesse exemplo, percebe-se que há limitações importantes no trabalho de tradução automática. Em termos de informação crítica, é preciso informar ao candidato que a caneta a ser usada durante a prova deve ser "esferográfica de tinta preta" e "fabricada em material transparente". Os avatares informam corretamente sobre o tipo de caneta, ainda que atinjam esse objetivo por não conhecerem a palavra esferográfica e por isso usarem datilologia na tradução desse trecho. Entretanto, a informação sobre o material da caneta é distorcida na tradução do Avatar 1, que informa a possibilidade de considerar materiais "VARIADOS". O Avatar 2 produz uma tradução mais adequada para essa informação. Interessante notar que o intérprete omite a necessidade de uso de caneta esferográfica. Claramente, trata-se de um lapso na execução da tradução, pois o intérprete 
VIII Congresso Brasileiro de Informática na Educação (CBIE 2019)

Anais do XXX Simpósio Brasileiro de Informática na Educação (SBIE 2019)

teria condições de fazê-la corretamente. Ainda, ambos avatares apresentaram dificuldade com a palavra "FABRICADA", sendo que o primeiro faz uso de um sinal em Libras que designa o substantivo "FÁBRICA/INDÚSTRIA"; e o segundo usa datilologia nessa palavra. Na resolução desse trecho, o intérprete altera o discurso, adequado-o ao contexto da Libras. O segundo ponto a ser discutido nessa sentença é a consequência da quebra da regra que está sendo informada. O Avatar 1 não consegue produzir uma tradução adequada. A tradução do Avatar 2 comete um equívoco que leva à produção de uma informação nova e equivocada, pois ele traduz as palavras "INSTRUÇÕES" e "PENA" como "ENSINAR" e "CASTIGO". Interpretando tais palavras em sequência produz-se o resultado referente a "ensinar um castigo". Tal tradução também não está adequada ao contexto.

\begin{tabular}{|c|c|}
\hline $\begin{array}{l}\text { Sentença } \\
\text { em análise }\end{array}$ & $\begin{array}{l}\text { "17.3 O preenchimento do Cartão-Resposta e da Folha de Redação deve, necessariamente, ser realizado } \\
\text { com caneta esferográfica de tinta preta, fabricada em material transparente, de acordo com as instruções } \\
\text { apresentadas, sob pena da impossibilidade de leitura óptica do Cartão-Resposta e da Folha de Redação." }\end{array}$ \\
\hline $\begin{array}{l}\text { Glosa para } \\
\text { avatar } 1\end{array}$ & $\begin{array}{c}1+7+3+\text { ESCREVER + CARTÃO + RESPOSTA + TEXTO + ATIVIDADE + PRECISAR + CANETA + } \\
E+S+F+E+R+O+G+R+A+F+I+C+A+\text { TINTA + PRETA + JÁ + FÁBRICA + MATERIAL + VARIADOS +CLARO + D+E + } \\
\text { COMBINAR + OBJETIVO + PLANO/MESA + SOBRE + IMPOSSIVEL + LER + O+P+T+I+C+A + CARTÃO + } \\
\text { RESPOSTA + PAPEL + ATIVIDADE. }\end{array}$ \\
\hline $\begin{array}{l}\text { Glosa para } \\
\text { avatar } 2\end{array}$ & 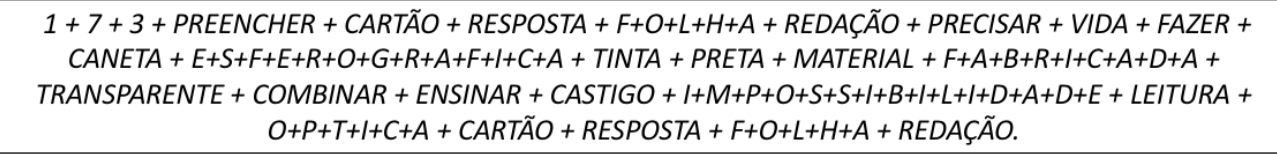 \\
\hline $\begin{array}{l}\text { Glosa para o } \\
\text { intérprete }\end{array}$ & $\begin{array}{c}\text { CARTÃO + RESPOSTA + QUESTÕES + TAMBÉM + CORREÇÃO + REDAÇÃO + ESCRITO + PRECISAR + CANETA + } \\
\text { COR + PRETA + TRANSPARENTE + COR + PRETA + SE + COR + OUTRA + ESCREVER + NÃO-PODER + LEITURA } \\
+ \text { ÓPTICA + CONSEGUIR-NÃO. }\end{array}$ \\
\hline
\end{tabular}

Figura 8. Sentença referente a procedimentos de realização da prova. Foco na precisão da informação transmitida e estruturas gramaticais das línguas

A sentença da Figura 8 ainda ilustra questões de estrutura gramatical. Os significados contextuais de preposições e locuções prepositivas, como "DE ACORDO COM", não possuem correspondentes diretos em Libras. Os avatares não tratam essa questão adequadamente. O Avatar 1 manteve a preposição "DE" com datilologia. Ambos os avatares colocam o "de acordo com" na forma do verbo "COMBINAR". Esse sentido é admissível, porém, o restante do discurso não esclarece adequadamente que "o combinado" significa "seguir instruções". O intérprete faz uma sentença condicional, explicando ao candidato que "SE" a regra for descumprida, não será possível realizar a leitura óptica. A repetição dos sinais "COR" e "PRETA" é necessária para compor uma sentença condicional com tópico. A composição da condicional "SE" e do tópico são feitas por meio de expressões faciais gramaticais. Além desta passagem, expressões faciais gramaticais são usadas na expressão negativa “CONSEGUIR-NÃO”. Nesse caso, a palavra "NÃO”, que nega a ação de "conseguir", é expressa via uma combinação de expressões não manuais.

A análise conduzida neste trabalho ilustrou a complexidade da automação da tradução português-Libras. Os softwares produziram traduções adequadas para algumas sentenças (ou trechos de sentenças), entretanto apresentaram algumas inadequações:

- A datilologia foi usada de forma excessiva nas traduções automáticas. Em nenhuma das sentenças discutidas houve uso de datilologia pelo intérprete.

- O português sinalizado está presente apenas nas traduções automáticas, mostrando que a ordem gramatical da Libras não está sendo respeitada. 
VIII Congresso Brasileiro de Informática na Educação (CBIE 2019)

Anais do XXX Simpósio Brasileiro de Informática na Educação (SBIE 2019)

- A síntese de expressões faciais morfológicas e gramaticais para os avatares é um requisito funcional importante neste tipo de aplicativo. Contudo, tal funcionalidade ainda não está sendo usada adequadamente nas traduções automáticas.

- Polissemia é um requisito fundamental para aplicativos de tradução e um problema importante na área de processamento de língua natural. Os avatares apresentaram dificuldade nas situações em que palavras polissêmicas foram usadas. Soluções já existentes para tratamento desta questão no processamento de línguas orais precisam ainda ser mapeadas para o contexto da tradução dos avatares.

- Sumarização é outro item que tem sido trabalhado no processamento automática da língua oral, é aplicado pelo intérprete na tradução língua oral-língua de sinais, mas cujo uso não foi observado no contexto dos softwares analisados.

\section{Considerações Finais}

Da análise descrita neste artigo, conclui-se que, apesar do potencial de impacto social que os softwares analisados (e similares) possuem, é prudente não utilizá-los como mediadores oficiais de comunicação. Em suas atuais condições, eles podem transmitir mensagens inadequadas e prejudicar usuários surdos, potencializando a sua condição de exclusão em contextos nos quais a precisão na comunicação é crucial, como é o caso do contexto do edital do Enem, que ilustra este trabalho. A aplicabilidade da tecnologia desses softwares vai além da função de tradução. Etapas necessárias para o processamento automático da língua de sinais servem como ferramentas simplificadas para suporte ao aprendizado de línguas de sinais [Bouzid et al. 2016, Madeo et al. 2010]. A qualidade gráfica dos avatares pode ser usada em aplicações que recebem um discurso já em língua de sinais como entrada e o proferem via avatares. Este é o caso de uma aplicação alemã que usa essa ferramenta para implementar uma comunicação precisa e inclusiva em locais públicos [Ebling and Glauert 2016]. A aceleração da melhoria da tradução automática português-Libras está atrelada à integração de aspectos de linguística teórica e aplicada contextualizada em língua de sinais, da linguística computacional considerando avanços que já são realidade para o caso as línguas orais, da computação gráfica e do estudo da interface homem-máquina para otimização de requisitos não funcionais como usabilidade e eficiência. Seguindo esta linha de trabalho, é possível vislumbrar um cenário otimista para a promoção da acessibilidade e inclusão das pessoas surdas.

\section{Referências}

Arroteia, J. (2005). O papel da marcação não-manual nas sentenças negativas em Língua de Sinais Brasileira (LSB). PhD thesis.

Battison, R. (1974). Phonological deletion in american sign language. Sign Language Studies, 5(1974):1-14.

Bouzid, Y., Khenissi, M. A., Essalmi, F., and Jemni, M. (2016). Using educational games for sign language learning-a signwriting learning game: Case study. Journal of Educational Technology \& Society, 19(1):129-141.

Brasil (2002). Lei $n^{0} 10.436$, de 24 de abril de 2002. dispõe sobre a língua brasileira de sinais-libras e dá outras providências. Diário Oficial da União.

Brasil (2005). Decreto $\mathrm{n}^{\mathrm{o}} 5.626$ de 22 de dezembro de 2005. regulamenta a lei $\mathrm{n}^{\mathrm{o}} 10$. Diário Oficial da União, 436. 
VIII Congresso Brasileiro de Informática na Educação (CBIE 2019)

Anais do XXX Simpósio Brasileiro de Informática na Educação (SBIE 2019)

Brasil (2015). Lei ${ }^{0} 13.146$, de 6 de julho de 2015. institui a lei brasileira de inclusão da pessoa com deficiência (estatuto da pessoa com deficiência). Diário Oficial da União.

Bryman, A. (2012). Social Research Methdos. Oxford University Press, 4th edition.

de Almeida Freitas, F., Peres, S. M., Lima, C. A. M., and Barbosa, F. V. (2017). Grammatical facial expression recognition in sign language discourse: a study at the syntax level. Information Systems Frontiers, 19(6):1243-1259.

de Lacerda, C. B. (1998). Um pouco da história das diferentes abordagens na educação dos surdos. Centro de Estudos Educação e Sociedade.

de Quadros, R. M. and Karnopp, L. B. (2009). Língua de sinais brasileira: estudos linguísticos. Artmed Editora.

de Quadros, R. M. and Schmiedt, M. L. (2006). Ideias para ensinar português para alunos surdos.

de Quadros, R. M., Szeremeta, J., Costa, E., Ferraro, M. L., Furtado, O., and Silva, J. C. (2009). Exame Prolibras.

Ebling, S. and Glauert, J. (2016). Building a swiss german sign language avatar with jasigning and evaluating it among the deaf community. Universal Access in the Information Society, 15(4):577-587.

El-Gayyar, M. M., Ibrahim, A. S., and Wahed, M. (2016). Translation from arabic speech to arabic sign language based on cloud computing. Egyptian Informatics Journal, 17(3):295-303.

Eryiğit, C., Köse, H., Kelepir, M., and Eryiğit, G. (2016). Building machine-readable knowledge representations for turkish sign language generation. Knowledge-Based Systems, 108:179-194.

Machado, M. C., Gomes, C. A. D., dos Santos, G. G. L., de Sousa, L. D., and Cancela, L. B. (2016). Inclusão social de deficientes auditivos por meio de tecnologias assistivas. In Anais do Encontro Virtual de Documentação em Software Livre e Congr. Intern. de Linguagem e Tecnologia Online, volume 6, pages 1-6.

Madeo, R. C. B., Peres, S. M., Bíscaro, H. H., Dias, D. B., and Boscarioli, C. (2010). A committee machine implementing the pattern recognition module for fingerspelling applications. In Symp. on Applied Computing, pages 954-958.

Mccleary, L., Viotti, E., and de Arantes Leite, T. (2010). Descrição das línguas sinalizadas: a questão da transcrição dos dados. ALFA: Revista de Linguística, 54(1):265-289.

Nair, M. S., Nimitha, A., and Idicula, S. M. (2016). Conversion of malayalam text to indian sign language using synthetic animation. In 2016 Int. Conf. on Next Generation Intelligent Systems (ICNGIS), pages 1-4. IEEE.

Santos, R. G. (2017). Aplicativos de libras, problema ou solução? ARTEFACTUM Revista de Estudos em Linguagens e Tecnologia, 14(1).

Stokoe, W. C. (1980). Sign language structure. Annual Rev. of Anthropol., 9(1):365-390.

Vieira, M. C., Corrêa, Y., Santarosa, L. M. C., and Biazus, M. C. V. (2014). Análise de expressões não-manuais em avatares tradutores de língua portuguesa para Libras. In Nuevas Ideas en Informática Educativa, volume 10, pages 172-183. 